\title{
Robotic assisted rehabilitation therapy for enhancing gait and motor function after stroke
}

\author{
Yun-Hee Kim ${ }^{1,2}$ \\ ${ }^{1}$ Department of Physical and Rehabilitation Medicine, Center for Prevention and Rehabilitation, Heart Vascular Stroke Institute, \\ Samsung Medical Center, Sungkyunkwan University School of Medicine, Seoul, Korea \\ ${ }^{2}$ Department of Health Sciences and Technology, Department of Medical Device Management \& Research, Department of Digital \\ Health, Samsung Advanced Institute for Health Sciences \& Technology, Sungkyunkwan University, Seoul, Korea
}

Received: June 7, 2019

Revised: June 15, 2019

Accepted: June 20, 2019

Corresponding author:

Yun-Hee Kim

Department of Physical and

Rehabilitation Medicine, Heart

Vascular Stroke Institute,

Samsung Medical Center,

Sungkyunkwan University

School of Medicine, 81 Irwon-

ro, Gangnam-gu, Seoul 06351, Korea

Tel: $+82-2-3410-2824$

E-mail:

yun1225.kim@samsung.com

\begin{abstract}
During the last two decades, there have been remarkable developments in electromechanical or robotic assisted rehabilitation therapy for promoting walking ability and upper extremity motor function. Robotic devices have made high-dosage and high-intensity rehabilitative training possible, therefore, useful for enhancing neural plasticity of the central nervous system in patients with brain diseases. Robotic assisted gait therapy showed evidence for both exoskeleton and end-effector devices when used alongside conventional physiotherapy in subacute stroke patients. However, robot-assisted gait training was not proven excellent to conventional physical therapy in stroke patients with chronic stage or when delivered alone. For upper limb motor function, robotic assisted therapy was comparable or superior to conventional therapy in improving motor function and activities of daily living for both subacute and chronic stage of stroke patients. Further studies are required to clarify the best protocol for individual patient's need and its transferring effect to the real world activities of patients. Conclusively, high quality researches and development of related technology may enhance the clinical and economic efficiency of robotic assisted rehabilitation therapy in near future. Robotic rehabilitation will certainly encounter a positive opportunity of technical development during the age of fourth industrial revolution.
\end{abstract}

Keywords: Motor disorders; Rehabilitation; Electromechanical or robotic assisted therapy; Stroke

\section{INTRODUCTION}

Stroke is a common, serious, and disabling global health-care problem and many patients survived from stroke experience disabilities including gait abnormality or deficits in upper extremity control [1]. About one-third of stroke survivors live with functional limitations in activities of daily living (ADL) and life-long residual disability even after 5 years post-stroke [2,3]. Stroke-related disabilities are a serious burden to both patients, family members, and society [4].
This is an Open Access article distributed under the terms of the Creative Commons Attribution Non-Commercial License (http:// creativecommons.org/licenses/ by-nc/4.0/). 
Well-coordinated multidisciplinary stroke care including comprehensive rehabilitation and robot-assisted therapy can give a potentially beneficial treatment option for motor recovery of the arm and gait [1].

After neural injury such as stroke, the ability of the brain or neural network to change, named "neuroplasticity," is the basic mechanism of functional recovery [5]. After focal ischemic brain injury, activity of remaining neural network is changed to optimize neural resources for recovery of function. During this period, inducing plasticity of neural network adjacent to the damaged area may enhance neural network reorganization and the functional restoration. The experience-dependent synaptic and circuit plasticity that remodels synaptic buttons and connections by repeated sensory experience play the most important role. High-dose intensive training [6] and repetitive practice of specific functional tasks [7] are essential for neural network reorganization and functional recovery after stroke.

During the last two decades, electromechanical or robotic technology has been developed to substitute for human actions by a reprogrammable, multifunctional manipulator to move specialized devices through variable programmed motions [8] and have been used to augment rehabilitation with greater sophistication of electro-mechanical components [9]. Robotic rehabilitation is universally well tolerated by stroke patients, and has been found to be an effective treatment for motor impairments after stroke. Rehabilitation using robot technology has the most important advantage of delivering high dosage and intensity intervention [10]. Because it is important to provide proper amount of errorless repetition to facilitate neural plasticity of motor system, robotic therapy became a promising technology for the rehabilitation of patients with motor disorders caused by stroke or other central nervous system disease [11]. Rehabilitation robots for stroke are usually designed to adapt for the patient's functional level and this process needs considerable technical flexibility. These techniques include but are not limited to passive and adaptive exercise, active assisted, active constrained and resistive exercise. The rehabilitation robot can apply constant therapy for long periods and allows for continuous monitoring of patient performance and progression that can be delivered to the therapist $[12,13]$. Different types of robots that can be used in rehabilitation include assistive robots that aid ADL and compensate for loss of function and therapeutic robots that provide task-specific training. Rehabilitation robots can also facilitate assessment procedures and improve their clinical value [14]. Exoskeleton as well as end-effector type robotic-assist systems were developed and applied for both gait and upper extremity motor function $[12,13,15]$. Exoskeletons have a structure, which resembles the human upper limb and robot joint axes match the limb joint axes. End-effector robots hold the patient's hands or feet at one point and generate forces at the interface [16]. Robotic aids for rehabilitation hold considerable promise but have not yet achieved strong clinical recommendations $[15,17]$. Barriers to adoption include the limited data on efficacy, the single-purpose design of existing robots, financial considerations, and clinicians' lack of familiarity with this technology [15]. Nevertheless, use of rehabilitation robotics has grown rapidly in recent decades, and a number of therapeutic rehabilitation robots have become available for research purpose and also for clinical use. In accordance with the results accumulated by new trials, there has been a quick change in clinical recommendations [14,16-23]. In this manuscript, recent research concerning robot devices for facilitating motor function of both gait and upper extremities, mainly focusing on the evidence of rehabilitation for stroke patients, are described.

\section{ROBOTIC ASSISTED THERAPY FOR IMPROVING GAIT FUNCTION}

During the past decade, many articles investigating the effect of electromechanical walking-assist devices, both exoskeletal and end-effector types, on gait function of stroke patients were published. Rehabilitation robots and electromechanical-assisted training devices for stroke patient have been used to locomotion restoration. Most of these devices incorporate body weight support along with treadmills or foot platforms. It was found that the exoskeletal type of robot devices were primarily used although the end-effector type were also utilized [17]. The main advantage of robotic devices over conventional gait training is that they reduce the need for intensive therapist support. A Cochrane systematic review updated in 2017 by Mehrholz et al. [21] reviewed 36 randomized controlled studies involving 1,472 participants. They concluded that electromechanical-assisted gait training combined with conventional physical therapy increased the odds becoming independently walking (odds ratio, 1.94; 95\% confidence interval [Cl], 1.39 to $2.71 ; \mathrm{P}<0.001$; moderate-quality evidence), but did not significantly increase walking velocity (mean difference [MD], $0.04 \mathrm{~m} / \mathrm{sec} ; 95 \% \mathrm{Cl}, 0.00$ to $0.09 ; \mathrm{P}=0.08$; low-quality evidence) or walking capacity (MD, $5.84 \mathrm{~m}$ walked in 6 minutes; $95 \% \mathrm{Cl},-16.73$ to 28.40 ; 
Table 1. Summary of robotic or electromechanical-assisted gait training

\begin{tabular}{|c|c|c|c|c|c|c|}
\hline Study & $\begin{array}{l}\text { Robotic } \\
\text { device }\end{array}$ & $\begin{array}{l}\text { No. of } \\
\text { participants }\end{array}$ & $\begin{array}{l}\text { Stroke } \\
\text { stage }\end{array}$ & Intensity & $\begin{array}{l}\text { Concomitant } \\
\text { therapy }\end{array}$ & $\begin{array}{c}\text { Summary } \\
\text { of results in } \\
\text { comparison } \\
\text { with } \\
\text { conventional } \\
\text { therapies }\end{array}$ \\
\hline \multicolumn{7}{|l|}{ Exoskeleton devices } \\
\hline Husemann et al. (2007) [27] & Lokomat & 32 & Subacute & 30 min, 5 times per week for 4 wk & Yes & More effective \\
\hline Hornby et al. (2008) [26] & Lokomat & 62 & Chronic & $30 \mathrm{~min}, 12$ sessions total & No & Less effective \\
\hline Jung et al. (2008) [28] & Lokomat & 25 & Chronic & 30 min, 3 times per week for 4 wk & Yes & More effective \\
\hline Hidler et al. (2009) [25] & Lokomat & 72 & Subacute & $1 \mathrm{hr}, 12$ sessions total & No & Less effective \\
\hline Westlake et al. (2009) [30] & Lokomat & 16 & Chronic & 30 min, 3 times per week for $4 \mathrm{wk}$ & Yes & More effective \\
\hline van Nunen et al. (2015) [47] & Lokomat & 30 & Subacute & 30 min, 2 times per week for 8 wk & No & No difference \\
\hline Ucar et al. (2014) [34] & Lokomat & 22 & Chronic & $30 \mathrm{~min}, 5$ times per week for $2 \mathrm{wk}$ & No & More effective \\
\hline Cho et al. (2015) [35] & Lokomat & 20 & Chronic & $30 \mathrm{~min}, 3$ times per week for $4 \mathrm{wk}$ & Yes & No difference \\
\hline Kim et al. (2015) [36] & Walkbot & 30 & Subacute & 40 min, 5 times per week for $4 \mathrm{wk}$ & Yes & More effective \\
\hline Taveggia et al. (2016) [37] & Lokomat & 28 & Chronic & $30 \mathrm{~min}, 5$ times per week for $5 \mathrm{wk}$ & Yes & More effective \\
\hline Bang et al. (2016) [48] & Lokomat & 18 & Chronic & 60 min, 5 times per week for 4 wk & No & More effective \\
\hline Han et al. (2016) [38] & Lokomat & 60 & Subacute & 30 min, 5 times per week for 4 wk & Yes & more effective \\
\hline Tanaka et al. (2012) [39] & GaitMaster & 12 & Chronic & $20 \mathrm{~min}, 2$ or $3 \mathrm{wk}$, total 12 session & No & More effective \\
\hline Waldman et al. (2013) [46] & $\begin{array}{l}\text { Portable } \\
\text { rehabilitation robot }\end{array}$ & 24 & Chronic & $60 \mathrm{~min}, 3$ times per week for $6 \mathrm{wk}$ & No & More effective \\
\hline Ochi et al. (2015) [43] & $\begin{array}{l}\text { Gait-assistance } \\
\text { robot }\end{array}$ & 26 & Subacute & 20 min, 5 times per week for $4 \mathrm{wk}$ & No & More effective \\
\hline Jayaraman et al. (2019) [44] & $\begin{array}{l}\text { SMA Honda Stride } \\
\text { Management Assist }\end{array}$ & 50 & Chronic & $\begin{array}{l}45 \mathrm{~min}, 3 \text { times per week for } \\
6-8 \mathrm{wk}, 18 \text { session total }\end{array}$ & Yes & More effective \\
\hline Lee et al. (2019) [49] & $\begin{array}{l}\text { GEMS, Gait } \\
\text { Enhancing and } \\
\text { Motivating System }\end{array}$ & 26 & Chronic & $\begin{array}{l}45 \text { min, } 3 \text { times per week for } 4 \text { wk, } \\
10 \text { session total }\end{array}$ & Yes & More effective \\
\hline \multicolumn{7}{|l|}{ End-effector-type devices } \\
\hline Werner et al. (2002) [55] & Gait trainer & 30 & Subacute & 20 min, 5 times per week for 4 wk & No & No difference \\
\hline Peurala et al. (2005) [52] & Gait trainer & 45 & Chronic & 20 min, 5 times per week for $3 \mathrm{wk}$ & No & No difference \\
\hline Tong et al. (2006) [54] & Gait trainer & 54 & Subacute & 20 min, 5 times per week for 4 wk & Yes & More effective \\
\hline Dias et al. (2007) [50] & Gait trainer & 40 & Chronic & $40 \mathrm{~min}, 5$ times per week for $4 \mathrm{wk}$ & No & No difference \\
\hline Pohl et al. (2007) [53] & Gait trainer & 155 & Subacute & 20 min, 5 times per week for 4 wk & No & More effective \\
\hline Peurala et al. (2009) [51] & Gait trainer & 56 & Subacute & 20 min, 5 times per week for $3 \mathrm{wk}$ & Yes & More effective \\
\hline Morone et al. (2011) [33] & Gait trainer & 48 & Subacute & 20 min, 5 times per week for $4 \mathrm{wk}$ & No & More effective \\
\hline Geroin et al. (2011) [56] & Gait trainer & 30 & Chronic & 50 min, 5 times per week for $2 \mathrm{wk}$ & Yes & More effective \\
\hline Chua et al. (2016) [57] & Gait trainer & 106 & Subacute & 20 min, 6 times per week for 8 wk & Yes & No difference \\
\hline
\end{tabular}



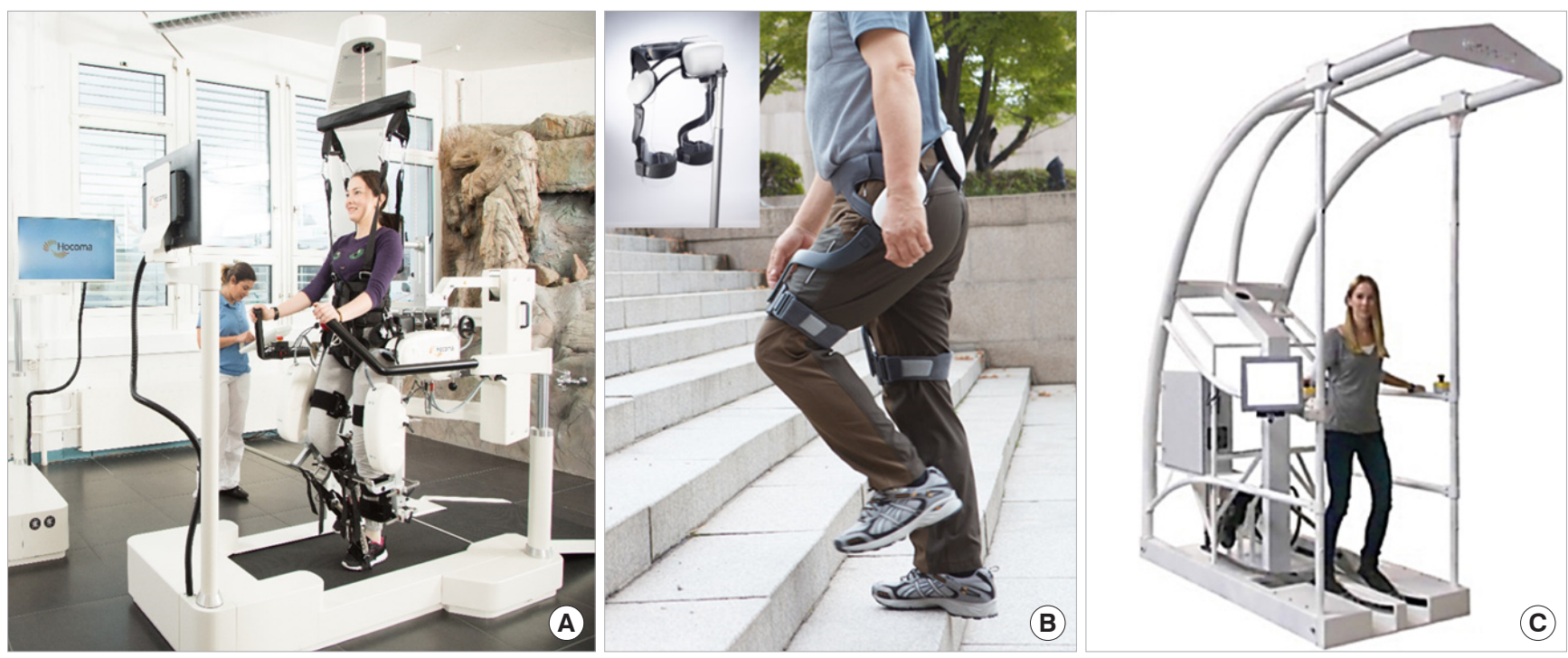

Fig. 1. Examples of robotic devices for training of gait. (A) Lokomat (Hocoma; https://www.hocoma.com/media-center/media-images/). (B) GEMS (Samsung Advanced Institute of Technology). (C) Gait Trainer GT II (Reha-Stim; https://reha-stim.com/gt-ii/).

$P=0.61$; very low-quality evidence).

Twenty-five randomized controlled trials that investigated the use of robotic assisted therapy with exoskeleton devices for improvement of gait function in patients with stroke were selected for review (Table 1, Fig. 1A, B) [24-49]. Two studies reported superior results from robotic assisted therapy in comparison with conventional; however, both trials recruited relatively small numbers of patients. Hornby et al. [26] performed a randomized controlled trial comparing the effects of robot-assisted gait training and manual facilitation with an assist-as-needed paradigm in patients with chronic stroke. In this trial, therapist-assisted training showed greater improvements in walking ability in ambulatory stroke survivors compared with a similar dosage of robot-assisted training. Furthermore, a later multicenter randomized trial by Hidler et al. [25] investigated the effect of robot-assisted therapy on gait function in patients with subacute stroke, and concluded that conventional gait training interventions appeared to be more effective than robot-assisted gait training for improving walking ability. These two reports agreed that conventional gait therapy was more effective than robot-assisted therapy for improving gait function after stroke while applied with similar training intensities. In contrast, other reports demonstrated similar or superior effects of robot-assisted therapy on gait recovery when applied in combination with conventional physiotherapy in patients with subacute stroke compared with conventional therapy alone [24,30]. Schwartz et al. [31] also concluded in a large participants study that robot-assisted gait training with regular physical therapy produced promis- ing effects on locomotor function in subacute stroke patients than regular physical therapy. Recently, studies revealed various effect of robot-assisted therapy on gait parameters. Bang and Shin [48] reported that a robot-assisted gait training group demonstrated better performance in gait speed, cadence, step length, and balance than a conventional training group as well as reducing the double limb support period. Han et al. [38] emphasized that patients receiving robot-assisted therapy showed improvements in arterial stiffness and increased peak aerobic capacity. Kim et al. [36] demonstrated that balance, gait function, and ADL were better in a robot-assisted training group compared with a conventional training group. Taveggia et al. [37] also demonstrated better functional independence in robot-assisted treatment compared to overground treatment. In summary, robotic assisted gait therapy may not be able to replace conventional physiotherapy for improving gait function in patients with stroke but rather recommended in combination with conventional physiotherapy. Patients with subacute stage of stroke who are not able to walk independently may be more likely to experience the beneficial effect of robot-assisted therapy. However, there is still insufficient evidence on the effect of robot-assisted therapy on gait function in the chronic stage of stroke. Furthermore, specific training protocols using different types of robotic assistance to fit individual patient's gait dysfunction may be required in the future. Exoskeletal robot assisted gait therapy for stroke hemiplegic patients also improved cardiopulmonary function compared with conventional gait training [24]. 
In contrast to exoskeletal type robotic devices, only a small number of reports investigated the effect of end-effector type robotic devices on gait function. Nine randomized controlled trials that compared end-effector-type devices with conventional therapies were reviewed (Table 1, Fig. 1C) [33,50-57]. Six studies used end-effector-type robotic gait training in subacute stroke patients and three studies conducted in chronic stroke patients. Four of the six subacute trials demonstrated that robot-assisted gait training combined with conventional physical therapy resulted in a greater improvement in locomotor function compared with conventional physical therapy alone $[33,51,53,54]$. In contrast, only one study in the chronic phase demonstrated a positive outcome in the robotic group. Therefore, the addition of robot-assisted therapy with end-effector-type devices to conventional physiotherapy can be recommended for improving gait function in patients with subacute stroke; however, no clear beneficial effect has been found in chronic stroke patients.

In conclusion, robotic gait training remains promising as an adjunctive therapy to conventional gait training. To maximize the benefit of robotic gait training, further studies should be performed for patient selection, optimal device type according to the functional level, and training protocols, etc.

\section{ROBOT-ASSISTED THERAPY FOR UPPER LIMB MOTOR FUNCTION}

Robot-assisted therapy can offer large amount of upper limb motor training for stroke patients. There are a variety of upper extremity robot types, consisting primarily of workstation devices used in a rehabilitation facility, but also including some wearable exoskeletal devices that can be used in a home environment [17]. A recent meta-analysis Cochrane review which included 45 trials (involving 1,619 participants) reported that electromechanical and robotic assisted arm training improved ADL scores (standardized mean difference [SMD], $0.31 ; 95 \% \mathrm{Cl}, 0.09$ to $0.52 ; \mathrm{P}=0.0005 ; 24$ studies, 957 participants, high-quality evidence), arm function (SMD, 0.32; 95\% $\mathrm{Cl}, 0.18$ to 0.46 ; $\mathrm{P}<0.0001$; 41 studies, 1,452 participants, high-quality evidence), and arm muscle strength (SMD, 0.46; $95 \% \mathrm{Cl}, 0.16$ to $0.77 ; \mathrm{P}=0.003 ; 23$ studies, 826 participants, high-quality evidence). Electromechanical and robot-assisted arm training did not increase the risk of participant drop out (risk difference, $0.00 ; 95 \% \mathrm{Cl},-0.02$ to $0.02 ; \mathrm{P}=0.93 ; 45$ studies, 1,619 participants, high-quality evidence), and adverse events were rare [23]. Twenty-four different electromechanical devices were described in the trials, which compared elec- tromechanical and robot-assisted arm training with a variety of other interventions. Participants were between 21 to 80 years of age, the duration of the trials ranged from 2 to 12 weeks, the size of the trials was between eight and 127 participants and the primary outcome differed between the included trials. Furthermore, the test for subgroup differences (between acute and subacute phase after stroke versus chronic phase after stroke) revealed no significant difference $(P=0.33$, level of heterogeneity $\left.\right|^{2}=0 \%$ ).

Without a doubt this analysis demonstrated more positive outcome than previous Cochrane review [20] which revealed weaker training effect of electromechanical and robotic assisted arm training on improving ADL, arm function, and arm muscle strength due to low or very low quality of evidence. Another metaanalysis by Veerbeek et al. [19] analyzed 38 trials (involving 1,206 participants) and reported significant but small improvements in motor control and muscle strength of the paretic arm and a negative effect on muscle tone by robot-assisted therapy of upper extremity in stroke patients. There was no positive effect on upper limb capacity and basic ADL.

Table 2 summarizes 32 randomized controlled trials that assessed the effect of robotic assisted therapy for improvement of upper limb motor function after stroke (Table 1, Fig. 2) [58-87]. Most of them used end-effector type robotic devices with the exception of seven studies which used exoskeleton type devices. Twenty of them performed the study for the chronic stage of stroke patients, 10 for the subacute phase, one for the acute phase, and one was undetermined. Electromechanical and robotic assisted arm training did not improve the risk of participant drop-out, but adverse events

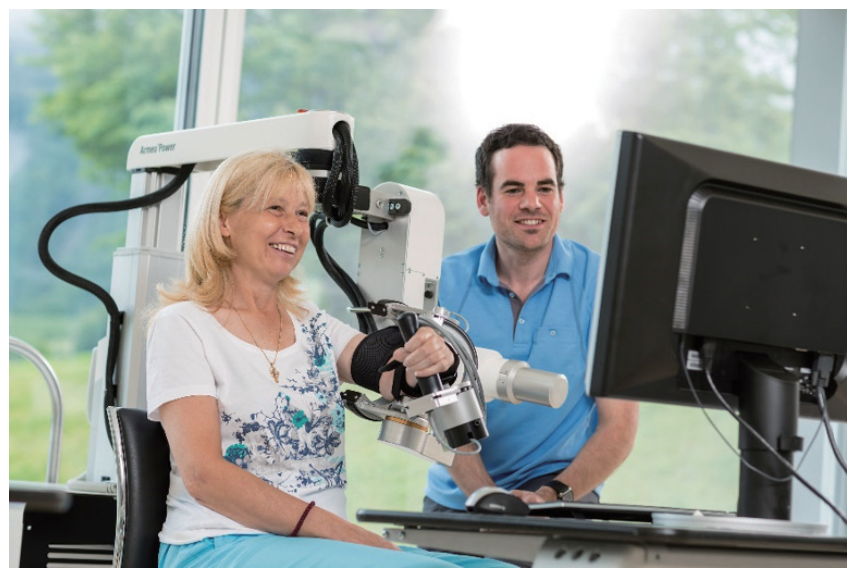

Fig. 2. Examples of robotic devices for motor training of upper limb. Armeo ${ }^{\circledR}$ Power (Hocoma; https://www.hocoma.com/mediacenter/media-images/); exoskeleton type upper limb training device. 
PRECISION AND FUTURE MEDICINE

Robotic assisted rehabilitation therapy

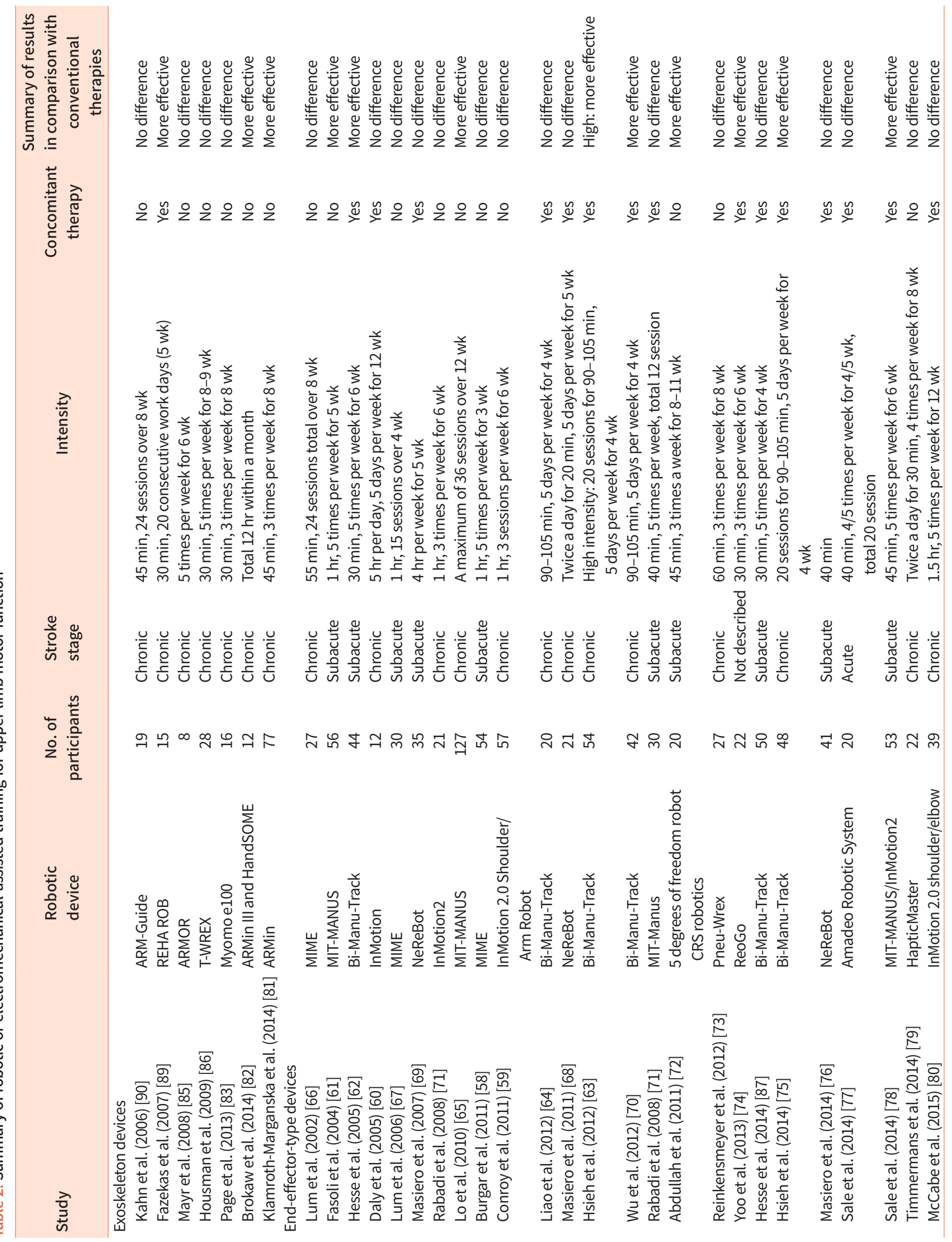


were rare. Each study used a diverse protocol and intensity of therapy; therefore, no uniform conclusion can be drawn. Indeed, more detailed analysis is needed to develop guidelines for individual stroke rehabilitation. Eleven studies reported better outcomes in upper extremity motor function compared with conventional treatment. A study by Fasoli et al. [61] consisting of 56 patients with subacute stroke reported that patients who received conventional therapy alone showed little improvement, whereas patients who received robotic training plus conventional therapy using end-effector type devices continued to improve in the latter half of the inpatient rehabilitation period. A study by Lo et al. [65] that recruited 127 chronic stroke patients reported that robot-assisted therapy and conventional therapy produced similar amounts of improvement after 12 weeks of treatment. However, after 36 weeks of therapy, the robotic assisted therapy achieved greater motor improvement than conventional therapy. Hsieh et al. [75] applied robotic devices with constraint-induced movement therapy and reported significantly increased Fugl-Meyer Assessment (FMA) scores in the robotic training group compared with the conventional therapy group and also found significantly better improvements in upper limb motor function in the higher-intensity robotic assisted training group [88]. In contrast, motor recovery of upper extremity did not significantly different between the lower intensity therapy and the control groups. These results suggest that the therapy intensity is the important variable of robot-assisted therapy for upper extremity motor recovery in chronic stroke patients. Two studies with subacute stroke patients suggested that additional robotic therapy showed greater improvements in ADL $[61,69]$; however, trials in chronic stroke patients demonstrated no additional improvement in ADL [63]. Eight trials used exoskeleton type robotic devices for upper extremity motor function in patients in the chronic stage of stroke. Fazekas et al. [89] reported a significantly better effect on spasticity in the robot-assisted therapy group than in the conventional therapy group. Other reports demonstrated no significant difference between robot-assisted therapy with exoskeleton devices and conventional therapies $[27,29,83,90]$. Therefore, the assisting effect of robotic devices on ADL was insufficient to draw a definite conclusion until the recent meta-analysis Cochrane review was published [23].

In summary, people who receive electromechanical and robotic assisted arm training after stroke might improve their $A D L$, arm function, and arm muscle strength; however, there were variations between the trials in the participant charac- teristics, measurements used, therapy types, and the intensity, duration, and amount of therapy. Moreover, further studies are needed to draw a definite conclusion whether the improving effect of robot-assisted training transferred to facilitating activities in real world for patients with stroke.

\section{ROBOTIC ASSISTED THERAPY FOR HAND MOTOR FUNCTION}

Eight randomized controlled trials using robotic devices for improving hand motor function of stroke patients were included in this review (Table 3) [22,91-98]. The type of robot and participants' characteristics were diverse; six of them applied end-effector type devices and three of them used exoskeleton type robot devices. Six of them performed the study for patients in the chronic stage of stroke, two for subacute stroke, and one undetermined stage. The outcomes of robotic assisted therapy on hand motor function were also variable; four studies out of nine demonstrated superior effects of robotic assisted training on hand motor function in comparison with conventional therapy for stroke patients and the remaining five studies did not demonstrate better functional outcome of robotic therapy. Three studies used exoskeleton type devices, two of which demonstrated a favorable effect in chronic stroke patients $[96,98]$. Out of the six studies that used end-effector type devices, only two showed favorable outcomes. Hwang et al. [93] demonstrated that end-effector type robotic assisted therapy provided dose-dependent improvements in hand function of chronic stroke patients. However, the trial was a single-center study with a relatively small number of participants. Orihuela-Espina et al. [95] reported positive results of robotic training in hand motor performance and FMA scores in the subacute stage of stroke. Other studies did not find significant differences between the robotic training group and the conventional therapy group in both FMA and hand dexterity test results. A recent study by Villafane et al. [22] also reported that robotic assisted mobilization performed in conjunction with traditional physical and occupational therapy showed no additional effect to the traditional rehabilitation in the treatment of pain and spasticity in hand paralysis after stroke. Well-designed large randomized controlled studies are needed in order to investigate the effect of electromechanical or robotic assisted therapy on hand motor function and $A D L$ of patients in different phases of stroke. 
Table 3. Summary of robotic or electromechnical-assisted hand motor training

\begin{tabular}{|c|c|c|c|c|c|c|}
\hline Study & $\begin{array}{l}\text { Robotic } \\
\text { device }\end{array}$ & $\begin{array}{l}\text { No. of } \\
\text { participants }\end{array}$ & $\begin{array}{l}\text { Stroke } \\
\text { stage }\end{array}$ & Intensity & $\begin{array}{c}\text { Concomitant } \\
\text { therapy }\end{array}$ & $\begin{array}{c}\text { Summary } \\
\text { of results in } \\
\text { comparison } \\
\text { with } \\
\text { conventional } \\
\text { therapies }\end{array}$ \\
\hline \multicolumn{7}{|l|}{ Exoskeleton devices } \\
\hline Takahashi et al. (2008) [98] & HAWARD & 13 & Chronic & $1.5 \mathrm{hr}, 5$ times per week for $3 \mathrm{wk}$ & No & More effective \\
\hline Kutner et al. (2010) [97] & Hand Mentor & 17 & Chronic & 60 hr over 3 wk & Yes & No difference \\
\hline Susanto et al. (2015) [96] & $\begin{array}{l}\text { Hand exoskeleton } \\
\text { robot }\end{array}$ & 19 & Chronic & $\begin{array}{l}60 \mathrm{~min}, 3-5 \text { times a week, } \\
\text { total } 20 \text { session within } 5 \mathrm{wk}\end{array}$ & No & More effective \\
\hline \multicolumn{7}{|l|}{ End-effector-type devices } \\
\hline Fischer et al. (2007) [92] & $\begin{array}{l}\text { Cable orthosis/ } \\
\text { pneumatic } \\
\text { orthosis }\end{array}$ & 15 & Chronic & $1 \mathrm{hr}, 3$ times per week for $6 \mathrm{wk}$ & No & No difference \\
\hline Connelly et al. (2010) [91] & PneuGlove & 14 & Not described & $1 \mathrm{hr}, 3$ times per week for $6 \mathrm{wk}$ & No & No difference \\
\hline Hwang et al. (2012) [93] & Amadeo & 17 & Chronic & $20 \mathrm{~min}, 20$ sessions total over $4 \mathrm{wk}$ & No & More effective \\
\hline Ang et al. (2014) [94] & Haptic knob robot & 21 & Chronic & $60 \mathrm{~min}, 3$ times per week for $6 \mathrm{wk}$ & Yes & No difference \\
\hline $\begin{array}{l}\text { Orihuela-Espina et al. } \\
\text { (2016) [95] }\end{array}$ & $\begin{array}{l}\text { Amadeus } \\
\text { Tyromotion }\end{array}$ & 17 & Subacute & 60 min, total 40 session & No & More effective \\
\hline Villafane et al. (2018) [22] & Gloreha & 32 & Subacute & 30 min, total 9 sessions & Yes & No difference \\
\hline
\end{tabular}

\section{CONCLUSION}

The results of well-designed studies using robotic devices for gait and motor function has resulted in changes to the description for practice guideline in stroke rehabilitation. Many reports have described the efficacy of robot-assisted therapy for improving gait and upper extremity motor function in patients with stroke. However, there is still a remarkable heterogeneity of the robotic devices and the participants' characteristics as well as the diversity of the study designs in the literature.

Electromechanical or robotic assisted walking devices was found to be more effective than conventional gait training at increasing early independent walking after stroke and could be considered for patients who would not otherwise practice walking. However, they should not be used in place of conventional gait therapy $[17,18,21]$. Overall, the role of robotic assisted gait therapy in stroke rehabilitation is an adjunct to rather than a replacement for conventional rehabilitation therapy. Electromechanical and robotic assisted arm training improved ADL, function, and muscle strength of the affected arm in people after stroke. Although there were variations between the trials in the intensity, duration, and amount of training, type of treatment, participant characteristics, and measurements used, the quality of evidence was high [23].

Robotic assisted therapy for stroke rehabilitation has achieved remarkable advances in recent decades and will be further advanced with collaboration of the fundamental elements of the forth industrial revolution such as artificial intelligence (Al) and internet of things (IoT) in the near future. Ongoing improvements of the related technology may enhance the clinical efficacy and economic efficiency of such devices. Such advances will lead robotic assisted therapy to being a standard therapeutic modality in stroke rehabilitation [11].

\section{CONFLICTS OF INTEREST}

No potential conflict of interest relevant to this article was reported.

\section{ACKNOWLEDGMENTS}

This article was supported by the National Research Foundation of Korea (NRF) grant funded by the Korea government (NRF-2017R1A2A1A05000730 and NRF-2017M3A9G5083690). 


\section{ORCID}

Yun-Hee Kim https://orcid.org/0000-0001-6101-8851

\section{REFERENCES}

1. Langhorne P, Bernhardt J, Kwakkel G. Stroke rehabilitation. Lancet 2011;377:1693-702.

2. Barker-Collo S, Feigin VL, Parag V, Lawes CM, Senior H. Auckland Stroke Outcomes Study. Part 2: cognition and functional outcomes 5 years poststroke. Neurology 2010; 75:1608-16.

3. Hankey GJ, Jamrozik K, Broadhurst RJ, Forbes S, Anderson CS. Long-term disability after first-ever stroke and related prognostic factors in the Perth Community Stroke Study, 1989-1990. Stroke 2002;33:1034-40.

4. Rigby H, Gubitz G, Phillips S. A systematic review of caregiver burden following stroke. Int J Stroke 2009;4:285-92.

5. Pekna M, Pekny M, Nilsson M. Modulation of neural plasticity as a basis for stroke rehabilitation. Stroke 2012;43:281928.

6. European Stroke Organisation (ESO) Executive Committee; ESO Writing Committee. Guidelines for management of ischaemic stroke and transient ischaemic attack 2008. Cerebrovasc Dis 2008;25:457-507.

7. Kwakkel G, Wagenaar RC, Twisk JW, Lankhorst GJ, Koetsier JC. Intensity of leg and arm training after primary middle-cerebral-artery stroke: a randomised trial. Lancet 1999;354:191-6.

8. Pignolo L. Robotics in neuro-rehabilitation. J Rehabil Med 2009;41:955-60.

9. Esquenazi A, Packel A. Robotic-assisted gait training and restoration. Am J Phys Med Rehabil 2012;91:S217-27.

10. Sivan M, O'Connor RJ, Makower S, Levesley M, Bhakta B. Systematic review of outcome measures used in the evaluation of robot-assisted upper limb exercise in stroke. J Rehabil Med 2011;43:181-9.

11. Chang WH, Kim YH. Robot-assisted therapy in stroke rehabilitation. J Stroke 2013;15:174-81.

12. Lum PS, Godfrey SB, Brokaw EB, Holley RJ, Nichols D. Robotic approaches for rehabilitation of hand function after stroke. Am J Phys Med Rehabil 2012;91:S242-54.

13. Mehrholz J, Pohl M. Electromechanical-assisted gait training after stroke: a systematic review comparing end-effector and exoskeleton devices. J Rehabil Med 2012;44:193-9.

14. Shirota C, van Asseldonk E, Matjacic Z, Vallery H, Barralon P, Maggioni S, et al. Robot-supported assessment of balance in standing and walking. J Neuroeng Rehabil 2017;14:80.

15. Stein J. Robotics in rehabilitation: technology as destiny. Am J Phys Med Rehabil 2012;91:S199-203.

16. Bertani R, Melegari C, De Cola MC, Bramanti A, Bramanti P, Calabro RS. Effects of robot-assisted upper limb rehabilitation in stroke patients: a systematic review with meta-analysis. Neurol Sci 2017;38:1561-9.

17. Winstein CJ, Stein J, Arena R, Bates B, Cherney LR, Cramer SC, et al. Guidelines for adult stroke rehabilitation and recovery: a guideline for healthcare professionals from the American Heart Association/American Stroke Association. Stroke 2016;47:e98-169.

18. Hebert D, Lindsay MP, McIntyre A, Kirton A, Rumney PG, Bagg $S$, et al. Canadian stroke best practice recommendations: Stroke rehabilitation practice guidelines, update 2015. Int J Stroke 2016;11:459-84.

19. Veerbeek JM, Langbroek-Amersfoort AC, van Wegen EE, Meskers CG, Kwakkel G. Effects of robot-assisted therapy for the upper limb after stroke. Neurorehabil Neural Repair 2017;31:107-21.

20. Mehrholz J, Pohl M, Platz T, Kugler J, Elsner B. Electromechanical and robot-assisted arm training for improving activities of daily living, arm function, and arm muscle strength after stroke. Cochrane Database Syst Rev 2015; 11:CD006876.

21. Mehrholz J, Thomas S, Werner C, Kugler J, Pohl M, Elsner B. Electromechanical-assisted training for walking after stroke. Cochrane Database Syst Rev 2017;5:CD006185.

22. Villafane JH, Taveggia G, Galeri S, Bissolotti L, Mulle C, Imperio G, et al. Efficacy of short-term robot-assisted rehabilitation in patients with hand paralysis after stroke: a randomized clinical trial. Hand (NY) 2018;13:95-102.

23. Mehrholz J, Pohl M, Platz T, Kugler J, Elsner B. Electromechanical and robot-assisted arm training for improving activities of daily living, arm function, and arm muscle strength after stroke. Cochrane Database Syst Rev 2018; 9:CD006876.

24. Chang WH, Kim MS, Huh JP, Lee PK, Kim YH. Effects of robot-assisted gait training on cardiopulmonary fitness in subacute stroke patients: a randomized controlled study. Neurorehabil Neural Repair 2012;26:318-24.

25. Hidler J, Nichols D, Pelliccio M, Brady K, Campbell DD, Kahn JH, et al. Multicenter randomized clinical trial evaluating the effectiveness of the Lokomat in subacute stroke. Neurorehabil Neural Repair 2009;23:5-13.

26. Hornby TG, Campbell DD, Kahn JH, Demott T, Moore JL, Roth HR. Enhanced gait-related improvements after ther- 
apist- versus robotic-assisted locomotor training in subjects with chronic stroke: a randomized controlled study. Stroke 2008;39:1786-92.

27. Husemann B, Muller F, Krewer C, Heller S, Koenig E. Effects of locomotion training with assistance of a robot-driven gait orthosis in hemiparetic patients after stroke: a randomized controlled pilot study. Stroke 2007;38:349-54.

28. Jung KH, Ha HG, Shin HJ, Ohn SH, Sung DH, Lee PK, et al. Effects of robot-assisted gait therapy on locomotor recovery in stroke patients. J Korean Acad Rehabil Med 2008;32:258-66.

29. Mayr A, Kofler M, Quirbach E, Matzak H, Frohlich K, Saltuari L. Prospective, blinded, randomized crossover study of gait rehabilitation in stroke patients using the Lokomat gait orthosis. Neurorehabil Neural Repair 2007;21:307-14.

30. Westlake KP, Patten C. Pilot study of Lokomat versus manual-assisted treadmill training for locomotor recovery post-stroke. J Neuroeng Rehabil 2009;6:18.

31. Schwartz I, Sajin A, Fisher I, Neeb M, Shochina M, Katz-Leurer $M$, et al. The effectiveness of locomotor therapy using robotic-assisted gait training in subacute stroke patients: a randomized controlled trial. PM R 2009;1:516-23.

32. Kelley CP, Childress J, Boake C, Noser EA. Over-ground and robotic-assisted locomotor training in adults with chronic stroke: a blinded randomized clinical trial. Disabil Rehabil Assist Technol 2013;8:161-8.

33. Morone G, Bragoni M, losa M, De Angelis D, Venturiero V, Coiro $P$, et al. Who may benefit from robotic-assisted gait training? A randomized clinical trial in patients with subacute stroke. Neurorehabil Neural Repair 2011;25:636-44.

34. Ucar DE, Paker N, Bugdayci D. Lokomat: a therapeutic chance for patients with chronic hemiplegia. NeuroRehabilitation 2014;34:447-53.

35. Cho DY, Park SW, Lee MJ, Park DS, Kim EJ. Effects of robot-assisted gait training on the balance and gait of chronic stroke patients: focus on dependent ambulators. J Phys Ther Sci 2015;27:3053-7.

36. Kim SY, Yang L, Park IJ, Kim EJ, Park MS, You SH, et al. Correction to "Effects of innovative WALKBOT robotic-assisted locomotor training on balance and gait recovery in hemiparetic stroke: a prospective, randomized, experimenter blinded case control study with a four-week follow-up". IEEE Trans Neural Syst Rehabil Eng 2015;23:1128.

37. Taveggia G, Borboni A, Mule C, Villafane JH, Negrini S. Conflicting results of robot-assisted versus usual gait training during postacute rehabilitation of stroke patients: a randomized clinical trial. Int J Rehabil Res 2016;39:29-35.
38. Han EY, Im SH, Kim BR, Seo MJ, Kim MO. Robot-assisted gait training improves brachial-ankle pulse wave velocity and peak aerobic capacity in subacute stroke patients with totally dependent ambulation: Randomized controlled trial. Medicine (Baltimore) 2016;95:e5078.

39. Tanaka N, Saitou H, Takao T, lizuka N, Okuno J, Yano H, et al. Effects of gait rehabilitation with a footpad-type locomotion interface in patients with chronic post-stroke hemiparesis: a pilot study. Clin Rehabil 2012;26:686-95.

40. Forrester LW, Roy A, Krywonis A, Kehs G, Krebs HI, Macko RF. Modular ankle robotics training in early subacute stroke: a randomized controlled pilot study. Neurorehabil Neural Repair 2014;28:678-87.

41. Stein J, Bishop L, Stein DJ, Wong CK. Gait training with a robotic leg brace after stroke: a randomized controlled pilot study. Am J Phys Med Rehabil 2014;93:987-94.

42. Buesing C, Fisch G, O'Donnell M, Shahidi I, Thomas L, Mummidisetty CK, et al. Effects of a wearable exoskeleton stride management assist system (SMA ${ }^{\circledR}$ ) on spatiotemporal gait characteristics in individuals after stroke: a randomized controlled trial. J Neuroeng Rehabil 2015;12:69.

43. Ochi M, Wada F, Saeki S, Hachisuka K. Gait training in subacute non-ambulatory stroke patients using a full weight-bearing gait-assistance robot: a prospective, randomized, open, blinded-endpoint trial. J Neurol Sci 2015; 353:130-6.

44. Jayaraman A, O'Brien MK, Madhavan S, Mummidisetty CK, Roth HR, Hohl K, et al. Stride management assist exoskeleton vs functional gait training in stroke: a randomized trial. Neurology 2019;92:e263-73.

45. Watanabe H, Tanaka N, Inuta T, Saitou H, Yanagi H. Locomotion improvement using a hybrid assistive limb in recovery phase stroke patients: a randomized controlled pilot study. Arch Phys Med Rehabil 2014;95:2006-12.

46. Waldman G, Yang CY, Ren Y, Liu L, Guo X, Harvey RL, et al. Effects of robot-guided passive stretching and active movement training of ankle and mobility impairments in stroke. NeuroRehabilitation 2013;32:625-34.

47. van Nunen MP, Gerrits KH, Konijnenbelt M, Janssen TW, de Haan A. Recovery of walking ability using a robotic device in subacute stroke patients: a randomized controlled study. Disabil Rehabil Assist Technol 2015;10:1418.

48. Bang DH, Shin WS. Effects of robot-assisted gait training on spatiotemporal gait parameters and balance in patients with chronic stroke: a randomized controlled pilot trial. NeuroRehabilitation 2016;38:343-9. 
49. Lee HJ, Lee SH, Seo KH, Lee MH, Chang WH, Choi BY, et al. Training for walking efficiency with a wearable hip-assist robot in stroke patients: a pilot randomized controlled trial. Stroke, In press.

50. Dias D, Lains J, Pereira A, Nunes R, Caldas J, Amaral C, et al. Can we improve gait skills in chronic hemiplegics? A randomised control trial with gait trainer. Eura Medicophys 2007;43:499-504.

51. Peurala SH, Airaksinen O, Huuskonen P, Jakala P, Juhakoski M, Sandell K, et al. Effects of intensive therapy using gait trainer or floor walking exercises early after stroke. J Rehabil Med 2009;41:166-73.

52. Peurala SH, Tarkka IM, Pitkanen K, Sivenius J. The effectiveness of body weight-supported gait training and floor walking in patients with chronic stroke. Arch Phys Med Rehabil 2005;86:1557-64.

53. Pohl M, Werner C, Holzgraefe M, Kroczek G, Mehrholz J, Wingendorf I, et al. Repetitive locomotor training and physiotherapy improve walking and basic activities of daily living after stroke: a single-blind, randomized multicentre trial (DEutsche GAngtrainerStudie, DEGAS). Clin Rehabil 2007;21:17-27.

54. Tong RK, Ng MF, Li LS. Effectiveness of gait training using an electromechanical gait trainer, with and without functional electric stimulation, in subacute stroke: a randomized controlled trial. Arch Phys Med Rehabil 2006;87:1298304.

55. Werner C, Von Frankenberg S, Treig T, Konrad M, Hesse S. Treadmill training with partial body weight support and an electromechanical gait trainer for restoration of gait in subacute stroke patients: a randomized crossover study. Stroke 2002;33:2895-901.

56. Geroin C, Picelli A, Munari D, Waldner A, Tomelleri C, Smania N. Combined transcranial direct current stimulation and robot-assisted gait training in patients with chronic stroke: a preliminary comparison. Clin Rehabil 2011;25: 537-48.

57. Chua J, Culpan J, Menon E. Efficacy of an electromechanical gait trainer poststroke in singapore: a randomized controlled trial. Arch Phys Med Rehabil 2016;97:683-90.

58. Burgar CG, Lum PS, Scremin AM, Garber SL, Van der Loos HF, Kenney D, et al. Robot-assisted upper-limb therapy in acute rehabilitation setting following stroke: Department of Veterans Affairs multisite clinical trial. J Rehabil Res Dev 2011;48:445-58.

59. Conroy SS, Whitall J, Dipietro L, Jones-Lush LM, Zhan M, Finley MA, et al. Effect of gravity on robot-assisted motor training after chronic stroke: a randomized trial. Arch Phys Med Rehabil 2011;92:1754-61.

60. Daly JJ, Hogan N, Perepezko EM, Krebs HI, Rogers JM, Goyal KS, et al. Response to upper-limb robotics and functional neuromuscular stimulation following stroke. J Rehabil Res Dev 2005;42:723-36.

61. Fasoli SE, Krebs HI, Ferraro M, Hogan N, Volpe BT. Does shorter rehabilitation limit potential recovery poststroke? Neurorehabil Neural Repair 2004;18:88-94.

62. Hesse S, Werner C, Pohl M, Rueckriem S, Mehrholz J, Lingnau ML. Computerized arm training improves the motor control of the severely affected arm after stroke: a single-blinded randomized trial in two centers. Stroke 2005;36:1960-6.

63. Hsieh YW, Wu CY, Lin KC, Yao G, Wu KY, Chang YJ. Dose-response relationship of robot-assisted stroke motor rehabilitation: the impact of initial motor status. Stroke 2012; 43:2729-34.

64. Liao WW, Wu CY, Hsieh YW, Lin KC, Chang WY. Effects of robot-assisted upper limb rehabilitation on daily function and real-world arm activity in patients with chronic stroke: a randomized controlled trial. Clin Rehabil 2012; 26:111-20.

65. Lo AC, Guarino PD, Richards LG, Haselkorn JK, Wittenberg GF, Federman DG, et al. Robot-assisted therapy for long-term upper-limb impairment after stroke. N Engl J Med 2010;362:1772-83.

66. Lum PS, Burgar CG, Shor PC, Majmundar M, Van der Loos M. Robot-assisted movement training compared with conventional therapy techniques for the rehabilitation of upper-limb motor function after stroke. Arch Phys Med Rehabil 2002;83:952-9.

67. Lum PS, Burgar CG, Van der Loos M, Shor PC, Majmundar M, Yap R. MIME robotic device for upper-limb neurorehabilitation in subacute stroke subjects: a follow-up study. J Rehabil Res Dev 2006;43:631-42.

68. Masiero S, Armani M, Rosati G. Upper-limb robot-assisted therapy in rehabilitation of acute stroke patients: focused review and results of new randomized controlled trial. J Rehabil Res Dev 2011;48:355-66.

69. Masiero S, Celia A, Rosati G, Armani M. Robotic-assisted rehabilitation of the upper limb after acute stroke. Arch Phys Med Rehabil 2007;88:142-9.

70. Wu CY, Yang CL, Chuang LL, Lin KC, Chen HC, Chen MD, et al. Effect of therapist-based versus robot-assisted bilateral arm training on motor control, functional performance, and quality of life after chronic stroke: a clinical 
trial. Phys Ther 2012;92:1006-16.

71. Rabadi M, Galgano M, Lynch D, Akerman M, Lesser M, Volpe B. A pilot study of activity-based therapy in the arm motor recovery post stroke: a randomized controlled trial. Clin Rehabil 2008;22:1071-82.

72. Abdullah HA, Tarry C, Lambert C, Barreca S, Allen BO. Results of clinicians using a therapeutic robotic system in an inpatient stroke rehabilitation unit. J Neuroeng Rehabil 2011;8:50.

73. Reinkensmeyer DJ, Wolbrecht ET, Chan V, Chou C, Cramer SC, Bobrow JE. Comparison of three-dimensional, assist-as-needed robotic arm/hand movement training provided with Pneu-WREX to conventional tabletop therapy after chronic stroke. Am J Phys Med Rehabil 2012;91: S232-41.

74. Yoo DH, Cha YJ, Kim SK, Lee JS. Effect of three-dimensional robot-assisted therapy on upper limb function of patients with stroke. J Phys Ther Sci 2013;25:407-9.

75. Hsieh YW, Lin KC, Horng YS, Wu CY, Wu TC, Ku FL. Sequential combination of robot-assisted therapy and constraint-induced therapy in stroke rehabilitation: a randomized controlled trial. J Neurol 2014;261:1037-45.

76. Masiero S, Armani M, Ferlini G, Rosati G, Rossi A. Randomized trial of a robotic assistive device for the upper extremity during early inpatient stroke rehabilitation. Neurorehabil Neural Repair 2014;28:377-86.

77. Sale P, Franceschini M, Mazzoleni S, Palma E, Agosti M, Posteraro F. Effects of upper limb robot-assisted therapy on motor recovery in subacute stroke patients. J Neuroeng Rehabil 2014;11:104.

78. Sale P, Mazzoleni S, Lombardi V, Galafate D, Massimiani MP, Posteraro F, et al. Recovery of hand function with robot-assisted therapy in acute stroke patients: a randomized-controlled trial. Int J Rehabil Res 2014;37:236-42.

79. Timmermans AA, Lemmens RJ, Monfrance M, Geers RP, Bakx W, Smeets RJ, et al. Effects of task-oriented robot training on arm function, activity, and quality of life in chronic stroke patients: a randomized controlled trial. J Neuroeng Rehabil 2014;11:45.

80. McCabe J, Monkiewicz M, Holcomb J, Pundik S, Daly JJ. Comparison of robotics, functional electrical stimulation, and motor learning methods for treatment of persistent upper extremity dysfunction after stroke: a randomized controlled trial. Arch Phys Med Rehabil 2015;96:981-90.

81. Klamroth-Marganska V, Blanco J, Campen K, Curt A, Dietz $V$, Ettlin T, et al. Three-dimensional, task-specific robot therapy of the arm after stroke: a multicentre, paral- lel-group randomised trial. Lancet Neurol 2014;13:159-66.

82. Brokaw EB, Nichols D, Holley RJ, Lum PS. Robotic therapy provides a stimulus for upper limb motor recovery after stroke that is complementary to and distinct from conventional therapy. Neurorehabil Neural Repair 2014;28:367-76.

83. Page SJ, Hill V, White S. Portable upper extremity robotics is as efficacious as upper extremity rehabilitative therapy: a randomized controlled pilot trial. Clin Rehabil 2013; 27:494-503.

84. Housman SJ, Scott KM, Reinkensmeyer DJ. A randomized controlled trial of gravity-supported, computer-enhanced arm exercise for individuals with severe hemiparesis. Neurorehabil Neural Repair 2009;23:505-14.

85. Mayr A, Kofler M, Saltuari L. ARMOR: an electromechanical robot for upper limb training following stroke. A prospective randomised controlled pilot study. Handchir Mikrochir Plast Chir 2008;40:66-73.

86. Housman SJ, Scott KM, Reinkensmeyer DJ. A randomized controlled trial of gravity-supported, computer-enhanced arm exercise for individuals with severe hemiparesis. Neurorehabil Neural Repair 2009;23:505-14.

87. Hesse S, Heß A, Werner CC, Kabbert N, Buschfort R. Effect on arm function and cost of robot-assisted group therapy in subacute patients with stroke and a moderately to severely affected arm: a randomized controlled trial. Clin Rehabil 2014;28:637-47.

88. Hsieh YW, Wu CY, Liao WW, Lin KC, Wu KY, Lee CY. Effects of treatment intensity in upper limb robot-assisted therapy for chronic stroke: a pilot randomized controlled trial. Neurorehabil Neural Repair 2011;25:503-11.

89. Fazekas G, Horvath M, Troznai T, Toth A. Robot-mediated upper limb physiotherapy for patients with spastic hemiparesis: a preliminary study. J Rehabil Med 2007;39:5802.

90. Kahn LE, Zygman ML, Rymer WZ, Reinkensmeyer DJ. Robot-assisted reaching exercise promotes arm movement recovery in chronic hemiparetic stroke: a randomized controlled pilot study. J Neuroeng Rehabil 2006;3:12.

91. Connelly L, Jia Y, Toro ML, Stoykov ME, Kenyon RV, Kamper DG. A pneumatic glove and immersive virtual reality environment for hand rehabilitative training after stroke. IEEE Trans Neural Syst Rehabil Eng 2010;18:551-9.

92. Fischer HC, Stubblefield K, Kline T, Luo X, Kenyon RV, Kamper DG. Hand rehabilitation following stroke: a pilot study of assisted finger extension training in a virtual environment. Top Stroke Rehabil 2007;14:1-12.

93. Hwang CH, Seong JW, Son DS. Individual finger synchro- 
nized robot-assisted hand rehabilitation in subacute to chronic stroke: a prospective randomized clinical trial of efficacy. Clin Rehabil 2012;26:696-704.

94. Ang KK, Guan C, Phua KS, Wang C, Zhou L, Tang KY, et al. Brain-computer interface-based robotic end effector system for wrist and hand rehabilitation: results of a threearmed randomized controlled trial for chronic stroke. Front Neuroeng 2014;7:30.

95. Orihuela-Espina F, Roldan GF, Sanchez-Villavicencio I, Palafox L, Leder R, Sucar LE, et al. Robot training for hand motor recovery in subacute stroke patients: a randomized controlled trial. J Hand Ther 2016;29:51-7.
96. Susanto EA, Tong RK, Ockenfeld C, Ho NS. Efficacy of robot-assisted fingers training in chronic stroke survivors: a pilot randomized-controlled trial. J Neuroeng Rehabil 2015;12:42.

97. Kutner NG, Zhang R, Butler AJ, Wolf SL, Alberts JL. Quality-of-life change associated with robotic-assisted therapy to improve hand motor function in patients with subacute stroke: a randomized clinical trial. Phys Ther 2010; 90:493-504.

98. Takahashi CD, Der-Yeghiaian L, Le V, Motiwala RR, Cramer SC. Robot-based hand motor therapy after stroke. Brain 2008;131:425-37. 